RESEARCH ARTICLE

\title{
Disability, Agency, and Subjectivity in Aparna Sen's Three Disability Films: Sati, House of Memories, and 15 Park Avenue
}

\section{Sreerupa Sengupta}

Department of English, Auburn University, USA

\section{Abstract}

This paper focuses on three films directed by Indian-Bengali filmmaker Aparna Sen: Sati (1989) (Bengali), Paromitar Ekdin (subtitled as House of Memories) (2000) (Bengali), and 15 Park Avenue (English) (2006). Set in three different time periods and geopolitical spaces, these films experiment with the tabooed concept of female disability in India. Through a close reading and detailed analysis of the films, this paper argues that disability in the subcontinent has an altogether different implication for women because they are more valued in terms of their bodies' cultural, social, and familial profitability or exchange value than their individual qualities. While disabled men are seen as unfortunate and objects of pity, disabled women are held culpable for shaming their family, community, and nation. In the subcontinent, disability is conveniently used to stigmatize women deviating from the normative duties their bodies should fulfill, including bearing children and being satisfactory sexual partners. This paper claims that disability is occasionally used as a discriminatory term irrespective of its medical validity. Sen does not forget to reiterate the fact that medical diagnosis is not a valid method in determining the lack of functionality of an individual. Uma, Khuku, and Mithi, are the specially-abled characters who are marginalized due to their deviation from "socially and politically constructed able-bodied or neurotypical norm" (Fraser 6). This chapter shows how Sen denies binary identity categories, such as abled-disabled, normal-abnormal, through a recognition of alternative ways of being. Sen's women thoroughly reject the superficial medical and cultural standards for cognitive and physical ability and attempt to resist their marginalization and silencing, however insignificant or negligible their attempt may appear. These films

Open Access

Citation: Sengupta, S. Disability, Agency, and Subjectivity in Aparna Sen's Three Disability Films: Sati, House of Memories, and 15 Park Avenue. Gender and Women's Studies. 2018; 1(1):5.

Received: Oct 24, 2017

Accepted: May 21, 2018

Published: June 05, 2018

Copyright: @ $\odot 2018$ Sengupta S. This is an open access article distributed under the terms of the Creative Commons Attribution License, which permits unrestricted use, distribution, and reproduction in any medium, provided the original author and source are credited.

Corresponding author:

Sreerupa Sengupta, Department of

English, Auburn University, USA

E-mail: szs0171@auburn.edu complicate the definition of disability by taking it out of the limits of clinically-diagnosed anatomical irregularities. Thus, this paper explores the above-average functionality and sensitivity of these women negotiating medically diagnosed or culturally imposed disabilities.

\section{Keywords}

Non-normative bodies, culturally-imposed disability vs. medically-diagnosed disability, screening of disability, embodied experience, agency vs. marginalization

\section{Disability and the Films of Aparna Sen}

Throughout her career as a filmmaker, Aparna Sen has been very vocal about women's alienation in the subcontinental cultural imagination. Though very reluctant to call herself a feminist, Sen's films depict the challenges of being a woman in an intricately gendered and hyper-patriarchal Indian society. This multitalented filmmaker manages to write the stories and screenplays of many of her films and has acted in some of them in important roles, including Paroma, Paromitar Ekdin, and Iti Mrinalini. By virtue of "working closely with prominent Bengali auteurs," she associates her filmmaking with the "sensibilities of mid to late twentieth-century Bengali auteurship" (Roy \& Sengupta, 53).

Being a daughter of legendary film critic, Chidananda Dasgupta, and a student of internationally-acclaimed filmmakers, Satyajit Ray and Mrinal Sen, Sen has been "trained in 
the art of realistic cinema and performance" (Roy \& Sengupta, 54). The tradition of Indian parallel cinema started with Satyajit Ray, Mrinal Sen, Ritwik Ghatak and has been advanced by Shyam Benegal, Girish Kanrad, Adoor Gopalakrishnan, Ketan Mehta, Mani Kaul, and Kumar Shahani. This tradition takes a leap with a host of very talented women filmmakers of whom Sen is one of the most prominent. Her English films, 36 Chowringhee Lane, Mr. and Mrs. Iyer, and 15 Park Avenue, extend her fame and viewership from the regional to the national platform. Her films are usually "realistic portrayals of social and familial issues that characterize parallel cinema" (55). However, she carves a niche by "nuancing the identity of the Indian woman through a pluralistic and polyvocal feminist lens" (56). Her female protagonists are "not merely products of the feminist movements in India - their sense of agency might have been influenced by the social climate, but their negotiation of that agency is unique to their specific circumstances" (56).

Interestingly enough, apart from her contributions in addressing issues of women's desire and choices, Sen should deserve additional acknowledgment for addressing the fairly unexplored terrain of women's disability in Indian cinema without sentimentalizing or unnecessarily glorifying it. Physical and mental disability pose numerous challenges and threats to the affected individuals but the gender of the sufferer further multiplies the challenge and complicates the situation. Though there are critically-acclaimed films that incorporate women's disability, including Koshish by Gulzar, Sadma by Balu Mahendra, Black by Sanjay Leela Bhansali, Barfi by Anurag Basu, Margarita with a Straw by Shonali Bose, they are very few in number in comparison to films projecting disabled men like Sparsh, U Me Aur Hum, Ghajini, Paa, My Name is Khan, Barfi, Iqbal, Tare Zameen Par, Mein Aisa Hi Hoon, Koi... Mil Gaya etc. Three of Sen's films project women negotiating their disability in a world confused, indifferent, and, most of the times, insensitive to their struggles.

Released in 1989, the film Sati presents a mute village girl of 19th century Bengal, who is married to a tree to be saved from untimely widowhood, as is predicted in her horoscope. Being mute, orphan Uma has been exploited by her extended family. She does all the household chores without complains but is still considered to be a perennial burden due to her disability. Unlike a woman from a wealthy family, who is capable of showering wealth on her prospective husband, she is unworthy of marriage-due to her disability and poverty. However, Sen carefully secures a space for the expression of Uma's desire that is equally legitimate and valid like any other normal girl of her age. Her silent body expresses an urge to be loved and caressed, manifests anger at the unabashed verbal and physical abuses of her family and shows the power to nurture and care by hugging her tree husband or taking care of the cattle. When the "respected" village school master has a forced sex with her in the absence of his wife, Uma returns to him for her sexual gratification. Uma's pregnancy banishes her from her family to a cowshed. She dies in a stormy night being crushed by the huge tree, supposedly her husband. Uma fails to avoid her fate reserved for her by patriarchy, religion, and history but Sen highlights her qualities that remain unaffected by her muteness. As a daughter she serves her family, as a faithful "wife," she does not leave her tree-husband in the face of danger, and as a loving human being, she shares her unconditional love for helpless creatures. Uma's silence can be read as a metaphorical silencing of many hapless Kulin Brahmin (Brahmins of highest order) girls who were burnt alive in the pyres of their deceased husbands during the nineteenth century. However, in an attempt to create an archetypal suffering woman, Sen does not ignore the double marginalization a disabled woman experiences in a society where women are already subalterns with a limited power of speech.

Paromitar Ekdin or House of Memories, was released in 2000. The film screens a mentally retarded girl, Khuku, around nineteen or twenty. Some characters in the film refer to her as schizophrenic. Khuku is obese and awkward in her movements. She is often scolded by the family members due to her ignorance about the basic table manners and for wasting food, and sometimes thrashed by her mother, Sanaka, for not combing her hair and taking medicines. The film shows how the family perceives Khuku as an embarrassment. Sanaka complains that Khuku burdens her throughout her life and restricts her mobility. She asserts that Khuku remains her liability since other family members do not show any concerns about her. Sen, without ignoring Khuku's awkwardness and clumsy approaches, meticulously depicts Khuku's inherent talent for singing along with her kindness and sensitivity. Khuku has a mesmerizing voice, and her singing talent has been given detailed attention in the film. 
When Khuku's sister-in-law, Paromita, leaves the house after her separation from her husband, Khuku gives Sanaka, company. Khuku remains by Sanaka's side till her death. When doctors fail to do much, Khuku advises her brothers to contact Paromita with whom Sanaka shares a special bond. Sanaka feels devastated when Paromita leaves the house. The film does not ignore Khuku's desire to be loved and her maternal quality. She dresses up as a bride on the day of her brother's marriage.She feeds her physically disabled nephew and tells him stories. She takes great care of an unwanted guest, Monida, Sanaka's childhood love interest, offers him food, and opens the radio for him to listen. Sen shows that a mentally-challenged person can be equally caring, sensible, and sympathetic to other's needs. When Paromita gives birth to a disabled child, Sanaka and Paromita decide to take him to a school for children with cerebral palsy where these children are given a caring and encouraging atmosphere to exhibit their talents in diverse fields. The conversation between Sanaka and Paromita, on their way back from the school, reveals how the disabled children in the school are equally talented and sensitive. Only people around them are too insensitive to give them their due love and support.

Sen's 2006 film, 15 Park Avenue, tells the story of a young woman suffering from schizophrenia with deep suicidal ideation. Mitali or Mithi lives in an imaginary world as a happy mother of five imaginary children and a proud wife of a well-settled imaginary husband. Throughout the movie, she lives in her utopia, and the movie concludes with her imaginary union with her husband and children in the patio of an imaginary house in Kolkata, addressed 15 Park Avenue. The flashbacks show that Mithi was a normal and shy girl in love with a young man, Joydeep, working in an advertising agency. She hesitantly accepted a challenging assignment as a journalist that required her to cover post-election violence in a small town near the disturbed Bengal-Bihar border. Though she was nervous, she decided to give it a shot to defend herself against people's comments about her lack of confidence and frequent job changes. She was brutally raped by a gang of goons in a hotel room, and Joydeep denies to marry a raped woman. The trauma of being raped and deserted triggered her dormant schizophrenic traits. Though Mithi's world does not have any reality orientation, Sen sensitively handles her utopia more as an alternative reality than imaginary or nonexistent. In a conversation between Mithi's elder sister Anjali and her physician Kunal, Anjali asks "What gives us the power to declare Mithi's reality as unreal? If she gets happiness from that reality why should we snatch it from her?" Sen, through Kunal, answers the question: "Who decides what is real?" Kunal states that people in position of power or with the ability to control decide the legitimacy of a reality. Like Uma, Mithi's world is fraught with multiple challenges, including people being over inquisitive or humiliating, her family members feeling burdened to live with a person mumbling incoherently, reacting to auditory hallucinations, and trying to engage in frequent self-harming behaviors.

In Cultures of Representation: Disability in World Cinema Contexts, Benjamin Fraser asserts the importance of studying films from diverse cultures in understanding disability as a culture-specific and geopolitically defined corporeal condition. According to Fraser, film, as a medium with higher "representational significance" becomes "a reflective mirror, a productive expression or theoretical ground for the integration of perceptions and concepts that informs our socially negotiated understanding of disability" (7). The major limitation of disability studies in India is the use of western methodological framework in understanding the "corporeal differences in the Indian cultural context" which bounds to be faulty (Anand, 36). The treatment of disability in indigenous cultural and artistic productions can help overcome this disregard for Indian historical experience of disability. Disability has been universally conceptualized as "a power relationship between people with impairments and non-disabled people that devalue or exclude disabled people from mainstream society" but since social practices radically differ from one society/culture to the other, "the reproduction of disablement" varies due to culture-specific differences in "attitudes, discourses, and symbolic representations" (Ghosh, 201).Western feminist disability studies offer an important framework for understanding the lived experiences of "bodies marked with impairment and sex" but the ways "subjectivity of a disabled female body [works] in structuring notions of femininity, desirability, and sexuality can widely vary across cultures (Ghosh, 201).

While discussing the complexities in gender construction in India, Nandini Ghosh asserts how construction of femininity or womanhood has been shaped by "cultural symbols, social ideologies, and...indigenous belief systems" (202). Women in India are often burdened with 
the expectations of being chaste, pure, and productive like the mythological women, Sita and Ahalya, who have gone through extreme levels of physical punishment to become acceptable to their husbands or male-dominated communities. This mythologically defined ideal womanhood was transferred to the political realms when nationalist movements against the British Raj extensively used women as tropes for indigenous cultural purity. Women of flesh and blood had to sacrifice their desire and passion to become abstract symbols of a pure and ideal nation purged off the corrupting influence of the occident. Women's physical confinement to the inner space of the household often called "antarmahal" or "zenana" is a manifestation of the spiritual inner core of mother India. Following this political and cultural legacy women in India are groomed to become "good" daughters and satisfactory wives and mothers who will not question their defined roles and spatial limits. Disability in this scenario is a terrible malady because it interferes with the image of a fertile and pure mother India that can proudly produce brave sons who revere and protect her purity (Ghosh 203). Disability in Indian religious and mythological texts and some commercial movies is presented as a punishment of some grave sin. In case of women, the implication of that sin is serious since it puts the religious, political, and sociocultural parameters of traditional Indian womanhood at risk. Sen's films with disabled/specially-abled protagonists are valuable in understanding the concept of disability "within the overarching framework of Indian reality" (Addlakha 1). Sen's Paromitar Ekdin projects two mothers who suffer maximum marginalization because their disabled offspring make them traitors in the economy of sexual exchange where women's reproductive and mothering quality is a vital product. The degree of marginalization suffered by the daughter-in-law, Paromita, is higher than the mother-in-law, Sanaka, because Sanaka, besides giving birth to a mentally-retarded girl, also is a mother of two able-bodied sons, and a normal daughter. For Paromita, the situation is bleak since her productivity does not have a favorable proof in form of able-bodied children. Paromita's husband abuses her for their son, Bablu's cerebral palsy and insults her family for having hidden genetically or sexuallytransmitted diseases. When Bablu is diagnosed with the cerebral palsy, Paromita's father-inlaw scorns Sanaka for selecting Paromita for their son without properly investigating the genetic history of her family. So Paromita's disabled child is a breach of trust on her part that frustrates her in-laws' expectations about a "productive" daughter-in-law aware of her relational obligations. Khuku, Paromita's sister-in-law, on the other hand, is completely excluded from any family affairs as a discarded family member who is devoid of all possibility of being a good daughter, wife, and mother. Paromita is appreciated for her beauty till she gives birth to her disabled child but Khuku remains a perennial embarrassment to her family for her obese and awkward body and deranged mind. While nobody cares about her, she becomes a primary cause of her mother's complete confinement to the four walls of the house. Multiple scenes of the film capture Sanaka's emotional outbursts.

Mithi in 15 Park Avenue is similarly a burden for her parents and unmarried elder sister, Anjali, who are stressed with her suicidal ideation and hallucination about an imaginary utopia. Anjali cannot marry due to her obligation towards Mithi. But the wide gap between the economic condition and social status of the two families makes Mithi and Khuku's experience different. Mithi belongs to an educated, enlightened, and affluent household. By virtue of being a college professor, Anjali expresses her frustration in a less crude and more sophisticated way than Sanaka. Mithi's family can appoint an attendant for her who takes care of her day-to-day needs but Khuku's family does not feel the need for spending extra money for a rejected member. So, the expectation from Khuku and Mithi are different. Mithi is not accused or cursed for not performing the normal duties of a daughter while Khuku is sometimes beaten, scorned, and chastised for not learning to take care of herself or not offering any service to anyone. Mithi's sister discusses Mithi's mental disability with doctors which makes her an informed participant in her sister's life, while Sanaka being little educated about this matter cannot do anything more than blaming her destiny. In both the films, Sen asserts the importance of being informed and educated about disability and its challenges. She incorporates this crucial component through two important characters: Kunal and Rajiv. Kunal is a psychiatrist in 15 Park Avenue who offers Anjali valuable advises and treatment procedures to address Mithi's schizophrenia. Rajiv is a documentary filmmaker who enlightens Paromita and Sanaka about the special qualities of mentally disabled children who desperately need their family and community's cooperation and support to excel. After having the conversation with Rajiv, Sanaka thinks about sending Khuku to the special school where they send Bablu. She learns to appreciate Khuku's talent as a singer or her maternal 
instincts.

Uma's situation in Sati is far worse than Mithi and Khuku because the historical time period in which the film is set adds to her challenges of being both a woman and a person suffering from speech impairment. Since there were no modern treatment methods available, and she belongs to an orthodox Kulin Brahmin family of $19^{\text {th }}$ century colonial Bengal that used to practice dehumanizing rituals that completely negate women's freedom and mobility, her disability is very harshly addressed. As she has speech impairment, she cannot be married to a decent groom. But her disability does not let her escape the rigid social custom of marrying a kulin Brahmin girl at a certain age, which should not go above 12 years. When her relatives come to know that her horoscope indicates towards immature widowhood, the family marries her to a tree to save her prospective husband. So, a woman's life is clearly less valuable than a man's. It is permissible to put a woman's life at risk to save a man's life, power, and prestige. But disability magnifies this inferiority by giving it a grotesque dimension. Uma is raped. Being mute she becomes more susceptible to male sexual aggression than normal girls of her age. No one in her family questions how she becomes pregnant because they only are concerned about their social prestige. So, they forcefully abort the child in her womb. Then they throw her out of the house. She starts living in the cowshed being completely unattended. While nobody expects Mithi and Khuku to get married, Uma is expected to marry at a certain age even if the husband is a tree so that her family does not fall from its status. When she dies being crushed by her tree husband on a stormy night, the Brahmins in the village consider her to be a sati, though in an inferior form. Sen screens her death along with another very young widow on her husband's funeral pyre. By collapsing the normal sati ritual where a widow is supposed to be burnt alive on her husband's pyre and the accidental death of Uma, Sen shows women's fate can hardly be changed in a dehumanizing patriarchy but the visible physical or psychological impairment makes their destiny unbearably grotesque.

Thus, Sen's film carefully differentiates between the different degrees of marginalization experienced by Paromita, Khuku, Sanaka, Mithi, and Uma depending on the contextual implications of either being disabled or giving birth to disabled offspring. While discussing the notion of bhalo meye (good girl) in Bengali culture, Nandini Ghosh shows through ethnographic research on orthopedically disabled women how an excessive preoccupation with the idea of a "complete woman" makes it an ordeal for physically-challenged Bengali women to lead a normal life of respect and love. Ghosh asserts in this context, since Indian women's "socialization into patriarchal ideologies results in internalizing notions of feminine beauty, attractiveness, and appropriate feminine behavior," there is "no space for deviation from fixed norms. Patriarchal/ability systems specify the visual nature of desirability in women, which, for disabled women, depends not only on their physical features in general but also on the kind and degree of disability" (212). In Sati, Uma is being raped by the married village school master because Uma's lack as a complete woman makes her a far less legitimized subject for craving than any normal woman. She is more appropriate for a clandestine pleasure. The school master has the notion that raping Uma is not a terrible offence because she is not marriageable like other normal women for whom sexual purity is a mandatory physicality to be acceptable and satisfying wives. Her family marries her to a tree, which they might have thought twice before considering if she was an able-bodied girl of marriageable age. It seems that for her own sake, she does not require a proper marriage. However, for the sake of her family's social prestige, she at least requires an ornamental marriage that could give her family's image a cosmetic boost. Similarly, if her accidental death can be given the flamboyance of the sati ritual, her family can easily have the claim to fame as the Kulin (highest order) Brahmin. Being physically disabled, Uma is to some extent aware that she is different from other normal girls of her age in a negative way and her muteness already disqualifies her in terms of her desirability. So, she accepts scorns, thrashing, and other verbal and physical abuses. Her financial status also contributes to her suffering. Sen shows how disability in a low-income family can rapidly multiply the hardship for the disabled individual because overcoming disability requires both money and sensitivity nurtured through proper education. However, though she is not eligible for enjoying a married life blessed with a man's love and joys of motherhood, she is not excluded from the punishment delegated to those violating the norms of being a proper woman. When she becomes pregnant, nobody empathizes with her or considers the fact that being a mute girl it is much more difficult for her to expose or resist the rapist. She does not have her own version of the event due to her silence through impairment. She receives severe treatment 
like forced abortion and complete desertion. If she was an able-bodied girl, she might not be forced to live in a cowshed. She accepts everything because being exposed to the notions of beauty and femininity from an early age like all Bengali girls of the time period, she adapts to the dehumanizing treatment.

The situation is a bit complicated for Mithi and Khuku. Their psychological disorders negate their awareness about the public perception of their insufficiency; Khuku thinks that she is eligible for expected feminine roles and does not understand why she accepts beating, thrashing, and scorns whenever she tries to behave as a wife or mother or a caring adult. Sen wonderfully depicts that in the scene where Khuku dresses up as a bride being inspired by her brother's marriage. When she comes face-to-face with her brother and shows her bridal make-up, he recites a nursery rhyme to dilute Khuku's desire to become a bride. The rhyme tells about a little girl going to her in-laws' house after marriage accompanied by her pet cat. Like the little girl's venture into the adult and unknown world in the rhyme, Khuku's desire is nothing but infantile to her family members. Like Khuku, Mithi also thinks that she is a loving wife and proud mother of three children. Her imagination is only given the status of a gibberish by people surrounding her. Sen's treatment of the internal spaces of mentally disabled women highlights the limitations of women's movement in India during the late twentieth century. Bhargavi Davar in her discussion about marginalization of women suffering from mental illness asserts that the political movements often ignore the necessity of dealing with the personal. According to Davar, feminist movement in India "reflected the dominant critical rationalist thinking of the time that material issues of immediate political and economic import were worthier of a studied interrogation than a befuddling philosophical realm of the private" (340). Sen deserves credit for her attempt to compensate the gap between the "feminist-political" and mentally disabled women's "repertoire of vulnerabilities, agencies and dynamic movements of selves" (341). In House of Memories and 15 Park Avenue, a personal and private space is created to offer the mentally challenged protagonists at least some experiences of, what Davar calls, "a consolidated self" because both Khuku and Mithi experience "emotional distress-led vulnerability when they find themselves denied or even robbed of the realm of the personal, where their most intimate belief systems, thoughts, emotions and embodied experiences are challenged or otherwise denied legitimacy" (341).

Khuku's belief of being a caring maternal figure has not been taken seriously. When Paromita shows Sanaka how Khuku is feeding her nephew, Bablu, telling him stories, Sanaka scolds Paromita for allowing Khuku to do that because as a mentally unstable person she is not fit to take care of any other person. Her lack of mental stability also contributes to her lack of personal hygiene. They curiously observe Khuku when she repeats the same advises to Bablu given to her by her brothers: "Do not waste food, don't you know how many people starve?" Sanaka and Paromita feel amused witnessing Khuku playing the role of a responsible adult. But at the very next moment, Khuku loses her balance when Bablu accidentally turns over the plate scattering food all over the place. She shouts at him and shakes him violently. Sanaka stops Khuku by beating and thrashing her. Sanaka's emotional outburst reveals her extreme frustration with a mentally disabled daughter. Paromita resists Sanaka from physically abusing Khuku and asks whether she has given Khuku the routine medications she requires to function in a more manageable ways. This scene captures Khuku both as a pathological subject and as a person with her own intimate belief system. Khuku's self-image as a caring person is not nullified by the filmmaker since this image is presented in multiple scenes of the film. One such scene is the interaction between Monida and Khuku. Monida is Sanaka's distant relative and one-time love interest. He is a regular visitor to the house. As Sanaka's husband and sons are against his visits, he comes during their absence. When nobody is there to welcome him, given the female members of the house taking afternoon naps, Khuku becomes an accommodating host. She makes him feel comfortable and at home. She even turns on the news on the radio realizing that the guest might feel bored sitting alone. But the film nonetheless shows that the cohabitation of khuku's self-image and the society's perception about her is almost impossible. Khuku constantly attempts to escape the "psychiatric labelling" as a mentally-retarded or schizophrenic woman by, what Davar explains as, "the process of recuperation and self-recovery" through meaningful role playing (342). An important part of this process is to frame a positive discourse of special ability against the discourse of exclusion based on the expectations of a predominantly male institution of medicine and psychiatry. The latter described mentally ill women as having "dependent, maladjusted, neurotic personality" (349). 
Mithi's problem has deeper roots. Unlike Khuku, she does not develop her mental disorder since childhood. Before the bouts of schizophrenia, she was a normal and attractive young girl in a serious relationship. The only occasion that informs us about her fragile mental health is the conversation between her fiancé, Joydeep, and her family members. Mithi's parents and elder sister, Anjali, warn Joydeep against the future challenges he may have as a husband because Mithi has dormant mental health issues. Joydeep agrees to marry her even after this warning because at that point of time, Mithi does not show any visible signs of psychological instability. Mithi is not rejected for being mentally fragile. Joydeep considers her unworthy because she is raped. His obsession with her chaste body and his eventual rejection of Mithi push her towards a state where she loses all reality orientation. She creates her own imaginary world with an imaginary family. So, her recuperation or self-recovery involves the obstacles of not only an impaired mind but also an unacceptable body. In order to overcome the notion of impurity attached to her body, she unconsciously adheres to the "fixity and permanence of a socially constructed corporeality" (Addlakha 224). Renu Addlakha in her discussion about body politics and disabled women shows how the sense of imperfection attached to a disabled female body releases it from the obligation of adhering to a fixed and permanent standard of desired femininity constructed by patriarchy. First, these women are perceived as asexual and second, they are deemed unworthy of normal duties and responsibilities of being a good daughter, wife, and mother. Mithi, by being a diligent and observant mother, tries to overcome the fact that she is incapable of a person's wife only because she is raped by a group of sexual predators. She literally lives her life as Joydeep's wife who is deeply concerned about her husband's safety. When she watches the news of Iraqi President Saddam Hussain being captured by the U.S. government, she bursts into tears because she believes that her husband Jojo (she used to address Joydeep as Jojo) will be harmed by Saddam's enemy because he works in a company in Iraq. She hallucinates her children and talks to them, scolds them, and cuddles them. She balances out Joydeep's rejection by accepting a life as Joydeep's wife and mother of his children. When after some years, Joydeep accidentally meets her and feels deep remorse to see her in the present state, Mithi does not recognize him. However, she asks his help in finding out her imaginary house at 15 Park Avenue.

Thus, Mithi, Khuku, and Uma play the role of a wife, though people surrounding them do not take their status as wives valid because none of them are married in a real sense. Addlakha explains that disabled women experience "the same physical changes, emotional anxieties and social conflicts... and sex drive" like normal women of the same age but they have "greater concerns about their bodies than their able-bodied counterparts" (227). They negotiate a selfhood with both a disabled body, in the case of Uma, and mind, in the cases of Mithi and Khuku, and "may produce an alternative aesthetics with a selective focus on abilitybased and moral ideals of selfhood" (227). For a woman, being a wife is one of the most crucial ideals of an ablest Indian culture so Uma finds culmination of her wifehood in caressing her tree husband and keeping her secret possessions in the hollows of its trunk. On the stormy night, the safest shelter she can think of is her tree-husband. Both Mithi and Uma try to overcome the stigma attached to their bodies through sexual abuse by trying to fit into the ideal image of satisfying wives and, in the case of Mithi, a caring mother of multiple children. Khuku finds satisfaction in seeing herself in the image of a bride or feeding her nephew as a mother.

Addlakha discusses how disabled women do not find "self-assurance and confidence in the functioning and attractiveness of the body" (228). This lack of self-assurance is visible in Mithi's repeated attempts to commit suicide, Khuku's confession about her disease in several occasions, and Uma's acceptance of the tree husband as a legitimate option. However, Sen's physically or mentally challenged protagonists seem to make an effort to "contest the social stereotypes that cast aspersions on their capacity to be sexual partners, homemakers, and mothers" (229). They clearly display their understanding about certain responsibilities that being a wife or mother involve. Khuku's dressing up as a bride or feeding his nephew should not be seen only as some sporadic desires or imitations. She takes care of her ailing mother more than any other able-bodied member of the family. She also offers advice to her brothers to alleviate her mother's mental trauma caused by Paromita's departure. Without sensitivity towards people in need of care, this gesture is not possible. Mithi's imaginary world may, on the surface, seem a child's play or a schizophrenic person's routine indulgence in hallucinatory moments but without an adequate sense of commitment, this repeated 
enactment of a motherly role is difficult. She understands what wifely and maternal obligations mean. Similarly, Uma may not be seen simply as a mute bovine creature who is oblivious of relational expectations and is only concerned with some primeval instincts. Her attempts to embrace the neglected, including the cattle and the tree she is married to, shows her empathy for others. These women's disability does not affect their sensitivity, empathy, and commitment which their able-bodied family members lack. Through them, Sen questions and complicates notions like ability, functionality, and desirability. Through the creation of "enabling relationship" between themselves and people surrounding them, these women open up the possibilities for their empowerment which cultural insularity and pathological labelling choose to ignore.

\section{References}

Addlakha, R. (2013) "Body Politics and Disabled Femininity: Perspectives of Adolescent Girls from Delhi." Disability Studies in India: Global Discourses, Local Realities, edited by Renu, A. Routledge, 220-240.

Anand, S. (2014). Disability Movement, Disability Rights and Disability Studies. Disability Studies in India, 12(2), 35-60.

Balki, R. (2009). Paa. MAD Entertainment Ltd.

Baweja, H. (2005). Mein Aisa Hi Hoon.

Basu, A. (2012). Barfi. Ronnie Screwvala; Pritam Chakraborty.

Bhansali, S.L. (2005). Black. Applause Entertainment Ltd.

Bose, S. (2014). Margarita with a Straw. Viacom 18 Motion Pictures.

Devgun, A. (2008). U Me Aur Hum.

Fraser, B. (2016). Cultures of Representation: Disability in World Cinema Contexts.

Wallflower Press.

Ghosh, N. (2013). Bhalo Meye: Cultural Construction of Gender and Disability in Bengal. Disability Studies in India, 201-219.

Gulzar. (1972). Koshish. Romu N.Sippy; Raj N.Sippy.

Johar, K. (2010). My Name is Khan. Fox Searchlight Pictures.

Khan, A. (2007). Taare Zameen Par. Aamir Khan Production.

Kukunoor, N. (2005). Iqbal. Mukta Searchlight Films.

Mahendra, B. (1983). Sadma. Romu N.Sippy; Raj N.Sippy.

Murugadoss, A. R. (2008). Ghajini. Geetha Arts.

Paranjpye, S. (1980). Sparsh. Basu Bhattacharya.

Roshan, R. (2003). Koi... Mil Gaya. Filmkraft Productions Pvt. Ltd.

Roy, M., \&, Sengupta, A. (2014). Women and Emergent Agency in the Cinema of Aparna

Sen. South Asian Popular Culture, 12(2), 53-71.

Sen, A. (2006). Fifteen Park Avenue. SPS Films.

Sen, A. (2000). House of Memories. The Dream Merchants.

Sen, A. (2010). Iti Mrinalini. SVF Films.-

Sen, A. (1984). Parama. Usha Enterprises.

Sen, A. (1989). Sati. NFDC.

Sen, A. (1981). 36 Chowringhee Lane. Sashi Kapoor Films.

Sen, A. (2003). Mr. and Mrs. lyer. N. Venkatesh. 